\title{
THE ETHICS OF CONDUCTING RESEARCH USING SOCIAL MEDIA: A DISCUSSION CASE ${ }^{1}$
}

In 2015, Samuel who was registered for a master's programme in the Department of Business Management, housed within the Faculty of Management and Commerce at a prominent university located in the Eastern Cape Province of South Africa, decided on a research topic in the area of social media service quality using the E-S-SERVQUAL model. Once he settled on a topic, the next step would be to choose the context in which he would conduct his study.

Samuel was an employee at a South African based bank for the past two years, had recently started to notice the influence of social media in the banking industry and the potential damage that social media could cause to a bank's reputation. At the next meeting with his supervisor, Samuel informed him that he had chosen to conduct his research study in the context of the South African banking industry, with a specific focus on social media service quality. Samuel met with his supervisor on a few occasions and they established that several studies on service quality and client loyalty had been conducted in developed countries in the banking industry, but few studies involved developing countries.

Samuel, with guidance from his supervisor, decided that he would contact those individuals that posted messages on the Facebook pages of the five main South African banks and send them each a private message asking them to participate in his service quality study with a link to the survey administered via a popular survey tool. He was soon ready to present his proposal to the Higher Degrees Committee of the faculty in order to gain their permission to continue with the study.

On the chosen day, Samuel presented his research proposal to the Faculty members, all of whom seemed interested in his project. They asked many questions, but Samuel noticed that the common theme centered around the issue of data collection. Not all members of the panel appeared convinced that his chosen method was ethical. The confusion was on how Facebook distinguished between the profile of an individual and a group page, and this was going to affect how Samuel approached the individuals on these pages requesting them to participate in the study. The committee commented that Samuel had not spent enough time determining whether or not his chosen data collection approach on Facebook was ethical. The Committee's recommendation was to request Samuel to return to his study proposal and to investigate the ethics of social media research thoroughly. The decision rested on whether it was ethical or not to collect data from clients identified on the Facebook pages of the respective banks.

\footnotetext{
${ }^{1}$ Copyright (C) 2018, Liezel Cilliers and Kim Viljoen. This case was prepared for the purpose of class discussion. Names and some information have been disguised. This case is published under a Creative Commons BY-NC license and originally appeared as a chapter in Transforming Society Using ICT: Contemporary Discussion Cases from Africa. Permission is granted to copy and distribute this case for non-commercial purposes, in both printed and electronic formats.
} 


\section{Samuel's Proposed Study}

Samuel's study was about the influence of social media service quality and client loyalty intentions in the South African banking industry. Samuel believed that social media had facilitated the development of a form of buzz marketing called 'electronic word-of-mouth (eWOM)', which involves modern consumers expressing their opinions and discussing their experiences on online platforms. He noted that Facebook had become a common interaction space for consumers to comment and complain about different products and services. This indicated to him that social media sites (such as Facebook) and their respective content needed to be thoroughly investigated to allow marketers to design effective social media marketing strategies. Social media was generally categorised by content type as well as the type of interaction that users engaged in. Thus, Facebook was regarded as a social connectivity tool. In terms of numbers, Instagram and Facebook were the fastest growing social media sites in South Africa. Facebook was specifically used by a quarter of all South Africans in their electronic communication activities.

Samuel believed that South African retail banks needed to examine how clients perceived their service quality so that they could improve it in a meaningful way. Part of the motivation for his study was that he noted in 2015 that there was a total combined 1686954 users on the Facebook pages of the five major South African banks, with 792226 users on FNB; 290382 users for Capitec; 237666 users for ABSA; 205735 users for Standard Bank; and 160945 users for Nedbank. This was a large number of clients and Samuel knew that these were the people he needed to gather information from. Samuel opted to use an online survey for data collection. From the data collected using the online survey, he estimated using statistical methods that he needed 375 people to complete the survey and thus give credibility to his results.

It was Samuel's plan to approach banking clients who had posted messages on the banks' Facebook pages and to ask them to participate in his survey. If they said 'no' or did not respond, he would leave them alone. If they agreed, he would send them a link to his online survey. The survey would investigate the influence of social media service quality and client loyalty intentions in the South African banking industry using the E-S-SERVQUAL model.

Samuel recognized that if he used this method his messages to each bank's clients had to be private and personalized; the messages should not be sent more than twice to avoid being categorised as SPAM. Samuel's supervisor warned him that his chosen data collection strategy would be a tedious process with a high likelihood of failure, but Samuel had always liked a challenge and looked forward to this phase of his research project. He also decided that no incentives would be offered to his research participants.

In his readings, he noted that several other studies had used this method to recruit respondents and it was regarded as a good method to attain good response rates. Public Facebook pages, such as the banks' pages, were open and accessible to all internet users with no 'friends' listings, unlike private Facebook pages. 'Friending' individuals on Facebook to obtain details of other friends for marketing or research purposes was known as 'harvesting' and was fraught with complications and regarded as unethical. Samuel would definitely not engage in harvesting and continually reminded himself that Facebook users had complete access to how others choose to communicate with them through the administration of their privacy settings.

Samuel's study was clearly set out in his mind, but he could not carry out the study if the Research Higher Degrees Committee did not approve it. As stated earlier, some of the committee members were concerned about the ethics of the study, specifically the method of recruiting respondents on Facebook. As a result that they did not give approval to the study and they asked him to revise his study proposal. 
Going back to the drawing board he decided that the best course of action for him would be to get more information related to the ethical usage of social media in research. He devised the following strategy for his investigation. He would start with a clear understanding of how universities, especially his university, dealt with research ethics. He also needed to try to understand the different laws that protected consumers and their information in South Africa. Hopefully, he could also find some guidelines for ethics in social media research from either local or international sources.

\section{The University's Research Ethics Policy and Relevant Statutes}

Academic research output at South African universities was considered pivotal to the very existence of each university, with each unit of research output producing subsidies from the Department of Education. Post graduate student throughput was particularly important and as a Masters student, Samuel needed to make sure that he made the right decisions in order to graduate in the specified period of time. During Samuel's initial investigation, he realised that his intended strategy for data collection method had never been used at the university. There was also a complete lack of literature relating to the application of this methodology in South Africa. He wondered why no one in South Africa had collected research data this way before. He also remembered that one of the faculty members had mentioned a few laws in South Africa that protected consumers. He felt that since the banks' clients were posting messages on public platforms, he merely wanted to request that they participate in a survey; he wasn't forcing them to be part of it and he certainly was not trying to sell them anything. He was doing real research! Clearly the situation was not as straightforward as Samuel initially thought.

Samuel soon realised that the concept of ethics in research had become so prominent over the last decade-both across the world and in South Africa, especially in the humanities and medical fieldsthat it was increasingly being legislated. There had always been issues related to ethics in research but the complex issues facing current researchers necessitated further open and honest discussion. The advent of the Internet and platforms such as social media made the discussions and issues more intricate. In a university context, all universities had to have ethics committees to govern the research that their academics and students conducted. There were a variety of types and levels of ethics committees that varied by institution. Nevertheless, each university must ensure they have a main umbrella Research Ethics Committee (REC). Where necessary, the REC must be registered with the Department of Health and constituted as per section 73 of the National Health Act (Act 61 of 2003). Foreign universities have the same types of ethics bodies but they are referred to as Internal (or Institutional) Review Boards (IRBs).

Samuel realised that each university in South Africa had its own research ethics policy, which governs how research is carried out by staff and students. However, these policies were generally very similar to each other and were based on internationally generated standards. The most common standards mentioned across the universities were the World Medical Association (WMA) Helsinki Declaration and the Singapore Statement of Research Integrity. The international ethics principles generally related to honesty, accountability, professional courtesy and fairness in all research activities. He also noted that most of the generated ethical guidelines had used medical research as their basis and had diffused from that point into other research areas. Samuel read all of this and pondered how important ethics in medical research really was, wondering, not for the first time, what the big issue was with his social media banking research - he certainly had no intention of harming anyone, nor was there any potential for harm that he could discern. His next step was to look into the research ethics policy at his own university. 


\section{The research ethics policy at Samuel's university}

Samuel decided to carry on with his investigation of his research design. The next logical step Samuel took was to locate the research ethics policy that was in place at his university. Here is an extract from the policy:

- $\quad$ All staff and students who conducted research under the ambit of the university name had to apply for ethical clearance and must be issued with a clearance certificate before they could collect data for their research.

- $\quad$ The rights and responsibilities of the university in the research process included the consistent provision of research and academic autonomy as well as ensuring a safe and healthy research environment.

- The rights and responsibilities of the researcher in the research process maintained that researchers needed to ensure the highest level of honesty in their research, they had to maintain acceptable ethical standards in their relevant disciplines, and they needed to ensure that respondents were treated in an acceptable manner throughout the research.

- $\quad$ Other ethical issues related to data storage and retention, authorship, publications, supervision of students, procedures for dealing with research misconduct, and protection of rights and dignity in human and animal research.

Samuel noted the importance of the section of the policy that focused on respecting respondents. He was particularly interested in the following points that involved protecting participants in the research process:

- $\quad$ Researchers were supposed to consider prior research ethics reviews and clearances when planning their research.

- $\quad$ Participants of the research should not be harmed in any manner during the course of the research.

- $\quad$ Particular attention needed to be paid to the ethics of conducting research with vulnerable groups such as children, the disabled or the elderly when designing the research project. Special precautions needed to be taken when working with these groups.

- $\quad$ Participants involved in the research should give informed, voluntary consent to participation in the research. This informed consent, along with the objectives of the research, should be explained to the participants and they should be told exactly what is expected from them. This all needed to be explained to the participants in a language they understand using terminology that they understand.

- $\quad$ Participants in research projects had the right to withdraw from the project at any given time.

- $\quad$ Of utmost importance was ensuring the privacy and confidentiality of participants and their information during the research process.

\section{Relevant South African Legal Acts}

After examining his university's research ethics policy, Samuel decided it was time that he also perused the different acts that protected the information of consumers in South Africa. After all, one of the concerns expressed by the Higher Degrees Committee was that Samuel might be transgressing the consumer rights of the clients of the banks by contacting them on Facebook. This meant that Samuel had to scrutinize the Electronic Communications and Transactions Act (ECTA), which was introduced in South Africa in 2002, the 2008 Consumer Protection Act (CPA), and the Protection of Personal Information (POPI) Act, which was promulgated in 2013. 
After reading extensively on the subject matter, Samuel discovered that both the ECTA and CPA stipulated that recipients of unsolicited communication had the right to opt out of further communication and could request information on where their contact details were obtained from. This meant that Samuel's Facebook messages to banking clients could be considered unsolicited communication. He then noted that the POPI Act was considered a major improvement of the other two Acts 9 (i.e. the ECTA and CPA). Most importantly, the POPI Act placed great emphasis on the type of relationships that existed between marketers and consumers. It limited the amount of unsolicited marketing communication with the consumer-either requiring 'opting-in' to receive marketing messages or some type of pre-existing relationship between consumer and marketer-for communication to take place.

This analysis of legislation did not help Samuel much and he became even more frustrated than before. After all, the consumers from whom he wanted to gather research were those that are posting public comments on the Facebook pages of the different banks' Facebook pages. Facebook pages are regarded as public platforms, and customers comments on them were in the public domain. The question remained, did any of these statutes suggest that Samuel should not be allowed to contact these people to ask if they would consider participating in his research?

\section{Research Guidelines for Social Media}

\section{SAMRA and ESOMAR Guidelines}

After undertaking his research, Samuel found that no university in South Africa had actually made specific provisions for social media research. Upon this discovery, Samuel decided to look at any guidelines provided by non-academic organisations. Considering that Samuel's study fell within the marketing discipline, he decided first to approach the South African Marketing Research Association (SAMRA) for some advice. He discovered that SAMRA prescribed to the guidelines for conducting online and social media research, which were promulgated by the World Association for Social, Opinion and Market Research (ESOMAR).

From SAMRA, Samuel discovered that there were core fundamental principles that applied to social media research. These included:

- $\quad$ Researchers were not allowed to use personal data collected on social media for any purpose other than marketing as well as social and opinion research.

- $\quad$ Researchers could not use personally identifiable information from social media platforms. For example, the details of a person or a quote from someone that could be traced directly back to them. A large section of ESOMAR's social media research guidelines included specifications regarding 'masking', which meant transforming raw data so that it would be difficult for others to find the data online and then identify the person to whom it was linked.

- $\quad$ Researchers needed to be transparent and clearly identify their research purposes.

- $\quad$ Researchers had to comply with all relevant national and international laws. Areas of special included:

o Social media research had to comply with national and international data privacy legislation and relevant requirements for notice, consent, accuracy, security and access when personally identifiable data was collected and stored. 
o By accessing online services, researchers were subject to the service owners' terms of use and/or website's intellectual property right clauses relating to unauthorised copying of material.

- It was critical that consent and agreement be obtained from participants; information from social media platforms could not be used without this consent. Further, when researchers interacted directly with users on social media, they also had to convey to them the purpose, role and how they woulduse any comments. They also needed to seek permission from users and the service owners to conduct their work and make sure that they did not misrepresent themselves as a genuine member of the social media space. The researcher's details also had to be provided to allow for contact and verification.

- Other key principles of the social media research guidelines related to similar general research ethics guidelines, relating to topics such as ensuring no harm, particularly for research involving vulnerable groups such as children.

Samuel noted specifically that the policy defined 'public social media' as follows:

This covers the majority of social media. It includes all spaces where access has been set by the website or the user to 'public' and entry is without any form of entry barrier. It can also include those where a username or password is required, but these are required for identification or site revenue reasons, rather than to protect the privacy of the data posted. Examples include public profile pages of social media networks; public micro-blogging posts; and many forums (including those where a username may be required, but is automatically granted, that is they are not moderated).

While Samuel found this all interesting, he still could not relate what he had learned to his research as the ESOMAR social media guidelines seemed to refer mainly to information being taken from social media spaces and used for primary research purposes. His study was not doing this; it was using Facebook as a platform to make contact with the population in his sampling frame. To get further clarity, he read the Guidelines for online sampling quality from ESOMAR. He decided he had better examine it as he was obtaining his sample online. He also decided that he must not lose track of the fact that the ESOMAR's social media research guidelines referred to 'service owner's terms of use', meaning that he should potentially look into Facebook's terms of use policy at a later stage to make sure that he was not transgressing any of its rules.

\section{Guidelines for online sampling quality}

Upon reading the online sampling quality guidelines, Samuel discovered that the key criteria for rigorous online sampling included the following:

- The identity of each research participant ought to be validated by using a variety of different personal variables.

- It must be ensured that no respondent completed a survey more than once.

- The level of engagement displayed by respondents during a survey needed to be measured and reported on.

- The identity and personal data of respondents needed to be protected.

- Special care needed to be taken with vulnerable groups such as young people and children.

- Generally good questionnaire practices ought to be employed, giving consideration to aspects such as the length of the questionnaire and its structure.

- All relevant laws, regulations and industry codes of conduct ought to be complied with. 
Samuel felt these guidelines had also not given an answer on his problem. He then went on to read Facebook's terms of use.

\section{Facebook's Terms of Use}

Anyone who registered on Facebook was required to observe these rules and ensure they did not transgress them. Upon careful reading the Facebook conditions, Samuel found the following important information regarding content, information sharing, safety and protection of Facebook users' rights (Exhibit 1 contains an extract of Facebook's terms of use accessed from https://www.facebook.com/legal/terms):

- $\quad$ Facebook users owned all their own content and information they posted on Facebook. Users controlled how it was shared through their privacy and application settings, but needed to note the following;

o For content that was covered by intellectual property (IP) rights, such as photos and videos, users gave such certain permissions, subject to their privacy and application settings. These permissions included granting a non-exclusive, transferable, sublicensable, royalty-free, worldwide license to Facebook to use of any IP content that they posted on or in connection with Facebook. This license ended when the user deleted their IP content or their account-unless that content had been shared with others and they had not deleted it.

o Users needed to understand that even when they deleted content on Facebook, it could persist in backup copies for a reasonable period of time.

o When users made use of an application on Facebook, the application could ask them for permission to access their content and information as well as content and information that others had shared with the user.

o Further, Facebook stated that when users published content or information using the Public setting, it meant that they are allowing everyone, including people not enrolled in Facebook, to access and use that information and to associate it with them.

- With regards to respecting the users' rights, Facebook advocated the following rules:

o Facebook specified that if users collected information from other users, they needed to: obtain their consent, make it clear who is collecting their information, and post a privacy policy explaining what information they collect and how they will use it.

- With respect to safety conditions, Facebook stipulated the following to users:

o They were not allowed to post unauthorised commercial communications or SPAM on Facebook.

o They were prohibited from collecting users' content or information, or otherwise accessing Facebook using automated means (such as harvesting bots, robots, spiders, or scrapers) without Facebook's prior permission.

o They were not supposed to engage in unlawful multi-level marketing on Facebook.

o They were not allowed to upload viruses or other malicious code on Facebook.

o They were not entitled to solicit login information or access an account belonging to someone else. 
o They were prohibited from bullying, intimidating, or harassing any user.

o They could not posting content that was hate speech, threatening, or pornographic; incited violence; or containing nudity or graphic or gratuitous violence.

o They also could not develop or operate a third-party application containing alcoholrelated, dating or other mature content without appropriate age-based restrictions.

o They were not allowed to use Facebook to do anything unlawful, misleading, malicious, or discriminatory.

o Further, they could not do anything that could disable, overburden, or impair the proper working or appearance of Facebook, such as a denial of service attack or interference with page rendering or other Facebook functionality.

- In regard to respecting users' rights, Facebook advocated the following rules:

o Users are not allowed to post content or take any action on Facebook that infringes or violates someone else's rights or the law.

o Facebook has the right to remove any content or information users post if they believe that it violates their policies and will then allow an appeal process if necessary. Facebook is also entitled to disable users' accounts if the infringements are severe.

o Facebook specifies that if users collect information from other users, they need to: obtain their consent, make it clear who is collecting their information, and post a privacy policy explaining what information they collect and how they will use it.

o Users are not allowed to post anyone's identification documents or sensitive financial information on Facebook.

o Facebook users cannot tag users or send email invitations to non-users without their consent.

After Samuel had spent a considerable amount of time researching this issue, he was no closer to a definitive answer.

\section{Global guidelines for online research}

Still with no solution in sight, Samuel decided to 'cast his net wide again' as it became clear that no one document was going to tell him what to do about his dilemma. He decided to look into basic online marketing guidelines (ESOMAR) that existed before the era of social media. Surely he could apply those same principles to social media. Samuel discovered that these principles were quite generic and did not present much new information to him. They related to the responsibilities of researchers, data protection, incentives, protection of personal data and so on. What Samuel found interesting was the section on e-mail and text solicitation. Some of the most pertinent points included:

- $\quad$ Local and national laws may vary in their treatment of text or short message service and e-mail messages and they should be adhered to.

- $\quad$ Researchers could not use any 'subterfuge' in obtaining e-mail addresses or mobile numbers and this included using public domains, using technologies or techniques without people being aware, and collecting research disguised as some other activity.

- $\quad$ Researchers could not use unsolicited e-mails or SMSs to recruit research participants; this meant that participants had not granted consent or perhaps did not have a reasonable expectation or agreement that they may receive such e-mails or text messages. Five conditions could signify agreement to participate:

o A substantive pre-existing relationship existed between the researcher and the potential respondents contacted.

o Where recipients of e-mails and texts have specifically opted-in for the online or mobile 
research.

o The message invitations to potential research participants clearly communicate who is conducting the research and details of the research, as well as the choice to be removed from future e-mail or text message contact.

o Participants in the e-mail or mobile phone sample were not recruited via unsolicited emails or texts messages.

- $\quad$ Social media had given rise to new types of research opportunities including community panels, market research online communities, crowd-sourcing, co-creation, netnography, blog mining and web scraping, with many more evolving. Researchers should observe the same ethical principles as per research conducted face-to-face, by mail or telephone. More specifically, the ESOMAR guidelines stated that:

Social media data often includes personally identifiable information. Many regulations in this area were developed before it was possible for one person to communicate with many on publicly accessible online platforms. Updates in privacy and data protection laws are still being developed and often lag changes in practices that have become generally accepted. Nonetheless, researchers must consult whatever local regulations or industry codes that might exist in jurisdictions where research isplanned. (ESOMAR 2011)

\section{The Decision}

At the next meeting with this supervisor, Samuel presented all of the research that he had found. His supervisor felt that he was now in a position to make an informed decision as to whether he should continue with the present study, or change the data collection method.

If Samuel decided to use a generic population, the supervisor offered to distribute a questionnaire to her first year class that consisted of 400 students, which would satisfy the original estimation of the study population. The drawback in this approach was that it would be difficult to determine if these students had actually made use of a bank's Facebook page before in a meaningful way. Plus, there was a concern that the results would not be truly generalisable. In addition, the supervisor pointed out that if Samuel continued with his original data collection method it would make the much needed and meaningful contribution to the theoretical foundation of knowledge regarding social media data collection methods in South Africa. After all the effort that Samuel had put in the topic of using social media as a data collection method, it would be a waste not to make use of it. However, if Samuel persisted with this data collection method, there was a possibility that the Higher Degrees Committee would reject his proposal yet again, which would further delay his study. Samuel was unclear as to whether he should argue his original method or adopt the easier route of collecting data from an accessible population, thus allowing him to complete his study much quicker.

With all the reading Samuel had done, he was also still faced with the issue that he had not found any conclusive evidence or recommendations as to how to collect data ethically from clients making use of a company's Facebook page. While there was a lot of guidance in terms of research ethics, this was only meant to inform researchers that they must align their research as best they could with the stated ethical guidelines. Thus, Samuel remained uncertain as to whether he had enough information to 
convince the Higher Degree Committee that his data collection method was ethical and was unsure how to proceed. It was essential that he make a decision soon in order to complete his degree in the prescribed two-year period. Samuel also needed to remember that once he had made his decision he needed to re-draft his research proposal to reflect the chosen data collection method and population, plus provide sufficient motivation for his selection and only then could he make his presentation to the Committee.

\section{References}

Facebook (2015) Facebook Statement of Rights and Responsibilities. [online] https://www.facebook.com/legal/terms. Accessed 30 June 2017

European Society for Opinion and Market Research (ESOMAR) (2011) ESOMAR Guidelines for Online Research. [Online] https://www.esomar.org/uploads/public/knowledge-and-standards/codes-andguidelines/ESOMAR_Guideline-for-online-research.pdf, Accessed 1 June 2016 


\section{Biography}

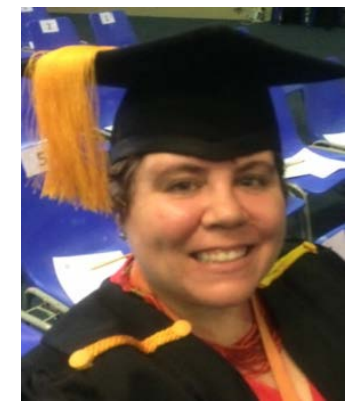

Dr Liezel Cilliers is a Senior Lecturer in the Department of Information Systems at the University of Fort Hare, South Africa. She holds a DPhil (Information Systems) and a Postgraduate Diploma in Higher Education. In 2016 she was awarded the Vice Chancellor's Excellence award in the category of experienced Teacher. She is also involved in the Health Informatics research group in the Health Science Faculty. Her research areas include technology in education, e-health and health informatics.

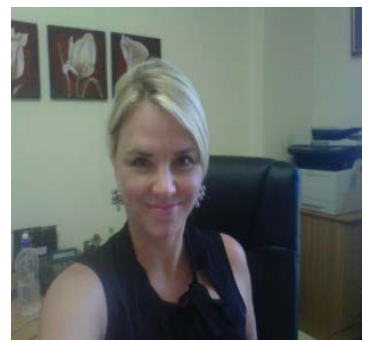

Dr Kim Viljoen is currently a Senior Lecturer in the Department of Business Management at the University of Fort Hare, South Africa, and holds a doctorate in marketing from the University of Johannesburg. Prior to joining academia, Kim owned and operated several businesses in the travel and tourism industry. Her research efforts are currently focused on social media service quality perception and service recovery with a predominant emphasis on the banking industry. 


\section{Exhibit 1: Extract of Facebook Statement of Rights and Responsibilities (January 2015)}

This Statement of Rights and Responsibilities ("Statement," "Terms," or "SRR") derives from the Facebook Principles, and is our terms of service that governs our relationship with users and others who interact with Facebook, as well as Facebook brands, products and services, which we call the "Facebook Services" or "Services". By using or accessing the Facebook Services, you agree to this Statement, as updated from time to time in accordance with Section 13 below. Additionally, you will find resources at the end of this document that help you understand how Facebook works.

Because Facebook provides a wide range of Services, we may ask you to review and accept supplemental terms that apply to your interaction with a specific app, product, or service. To the extent those supplemental terms conflict with this SRR, the supplemental terms associated with the app, product, or service govern with respect to your use of such app, product or service to the extent of the conflict.

\section{Privacy}

Your privacy is very important to us. We designed our Data Policy to make important disclosures about how you can use Facebook to share with others and how we collect and can use your content and information. We encourage you to read the Data Policy, and to use it to help you make informed decisions.

\section{Sharing Your Content and Information}

You own all of the content and information you post on Facebook, and you can control how it is shared through your privacy and application settings. In addition:

- For content that is covered by intellectual property rights, like photos and videos (IP content), you specifically give us the following permission, subject to your privacy and application settings: you grant us a non-exclusive, transferable, sub-licensable, royalty-free, worldwide license to use any IP content that you post on or in connection with Facebook (IP License). This IP License ends when you delete your IP content or your account unless your content has been shared with others, and they have not deleted it.

- When you delete IP content, it is deleted in a manner similar to emptying the recycle bin on a computer. However, you understand that removed content may persist in backup copies for a reasonable period of time (but will not be available to others).

- When you use an application, the application may ask for your permission to access your content and information as well as content and information that others have shared with you. We require applications to respect your privacy, and your agreement with that application will control how the application can use, store, and transfer that content and information. (To learn more about Platform, including how you can control what information other people may share with applications, read our Data Policy and Platform Page.)

- When you publish content or information using the Public setting, it means that you are allowing everyone, including people off of Facebook, to access and use that information, and to 
associate it with you (i.e., your name and profile picture).

- We always appreciate your feedback or other suggestions about Facebook, but you understand that we may use your feedback or suggestions without any obligation to compensate you for them (just as you have no obligation to offer them).

\section{Safety}

We do our best to keep Facebook safe, but we cannot guarantee it. We need your help to keep Facebook safe, which includes the following commitments by you:

- You will not post unauthorized commercial communications (such as spam) on Facebook.

- You will not collect users' content or information, or otherwise access Facebook, using automated means (such as harvesting bots, robots, spiders, or scrapers) without our prior permission.

- You will not engage in unlawful multi-level marketing, such as a pyramid scheme, on Facebook.

- You will not upload viruses or other malicious code.

- You will not solicit login information or access an account belonging to someone else.

- You will not bully, intimidate, or harass any user.

- You will not post content that: is hate speech, threatening, or pornographic; incites violence; or contains nudity or graphic or gratuitous violence.

- You will not develop or operate a third-party application containing alcohol-related, dating or other mature content (including advertisements) without appropriate age-based restrictions.

- You will not use Facebook to do anything unlawful, misleading, malicious, or discriminatory.

- You will not do anything that could disable, overburden, or impair the proper working or appearance of Facebook, such as a denial of service attack or interference with page rendering or other Facebook functionality.

- You will not facilitate or encourage any violations of this Statement or our policies.

\section{Registration and Account Security}

Facebook users provide their real names and information, and we need your help to keep it that way. Here are some commitments you make to us relating to registering and maintaining the security of your account:

- You will not provide any false personal information on Facebook, or create an account for anyone other than yourself without permission.

- You will not create more than one personal account. 
- If we disable your account, you will not create another one without our permission.

- You will not use your personal timeline primarily for your own commercial gain, and will use a Facebook Page for such purposes.

- You will not use Facebook if you are under 13.

- You will not use Facebook if you are a convicted sex offender.

- You will keep your contact information accurate and up-to-date.

- You will not share your password (or in the case of developers, your secret key), let anyone else access your account, or do anything else that might jeopardize the security of your account.

- You will not transfer your account (including any Page or application you administer) to anyone without first getting our written permission.

- If you select a username or similar identifier for your account or Page, we reserve the right to remove or reclaim it if we believe it is appropriate (such as when a trademark owner complains about a username that does not closely relate to a user's actual name).

\section{Protecting Other People's Rights}

We respect other people's rights, and expect you to do the same:

- You will not post content or take any action on Facebook that infringes or violates someone else's rights or otherwise violates the law.

- We can remove any content or information you post on Facebook if we believe that it violates this Statement or our policies.

- We provide you with tools to help you protect your intellectual property rights. To learn more, visit our How to Report Claims of Intellectual Property Infringement page.

- If we remove your content for infringing someone else's copyright, and you believe we removed it by mistake, we will provide you with an opportunity to appeal.

- If you repeatedly infringe other people's intellectual property rights, we will disable your account when appropriate.

- You will not use our copyrights or Trademarks or any confusingly similar marks, except as expressly permitted by our Brand Usage Guidelines or with our prior written permission.

- If you collect information from users, you will: obtain their consent, make it clear you (and not Facebook) are the one collecting their information, and post a privacy policy explaining what information you collect and how you will use it.

- You will not post anyone's identification documents or sensitive financial information on Facebook.

- You will not tag users or send email invitations to non-users without their consent.

Facebook offers social reporting tools to enable users to provide feedback about tagging. 


\section{Disputes}

You will resolve any claim, cause of action or dispute (claim) you have with us arising out of or relating to this Statement or Facebook exclusively in the U.S. District Court for the Northern District of California or a state court located in San Mateo County, and you agree to submit to the personal jurisdiction of such courts for the purpose of litigating all such claims. The laws of the State of California will govern this Statement, as well as any claim that might arise between you and us, without regard to conflict of law provisions.

If anyone brings a claim against us related to your actions, content or information on Facebook, you will indemnify and hold us harmless from and against all damages, losses, and expenses of any kind (including reasonable legal fees and costs) related to such claim. Although we provide rules for user conduct, we do not control or direct users' actions on Facebook and are not responsible for the content or information users transmit or share on Facebook. We are not responsible for any offensive, inappropriate, obscene, unlawful or otherwise objectionable content or information you may encounter on Facebook. We are not responsible for the conduct, whether online or offline, of any user of Facebook.

We try to keep Facebook up, bug-free, and safe, but you use it at your own risk. We are providing Facebook as is without any express or implied warranties including, but not limited to, implied warranties of merchantability, fitness for a particular purpose, and non-infringement. We do not guarantee that Facebook will always be safe, secure or error-free or that Facebook will always function without disruptions, delays or imperfections. Facebook is not responsible for the actions, content, information, or data of third parties, and you release us, our directors, officers, employees, and agents from any claims and damages, known and unknown, arising out of or in any way connected with any claim you have against any such third parties. If you are a California resident, you waive California civil code §1542, which says: a general release does not extend to claims which the creditor does not know or suspect to exist in his or her favor at the time of executing the release, which if known by him or her must have materially affected his or her settlement with the debtor. We will not be liable to you for any lost profits or other consequential, special, indirect, or incidental damages arising out of or in connection with this statement or Facebook, even if we have been advised of the possibility of such damages. Our aggregate liability arising out of this statement or Facebook will not exceed the greater of one hundred dollars (\$100) or the amount you have paid us in the past twelve months. Applicable law may not allow the limitation or exclusion of liability or incidental or consequential damages, so the above limitation or exclusion may not apply to you. In such cases, Facebook's liability will be limited to the fullest extent permitted by applicable law.

Source: https://www.facebook.com/legal/terms 